\title{
Patient outcomes following GPs' educations about COPD: a cluster randomized controlled trial
}

\author{
Hanna Sandelowsky $\mathbb{D}^{1,2,3 凶}$, Ingvar Krakau ${ }^{1}$, Sonja Modin ${ }^{3}$, Björn Ställberg $\mathbb{D}^{4}$, Sven-Erik Johansson ${ }^{5}$ and Anna Nager ${ }^{3}$
}

This study aimed to compare patient outcomes following case method learning and traditional lectures as methods for continuing medical education (CME) about chronic obstructive pulmonary disease (COPD) for general practitioners (GPs) in Sweden. In a pragmatic cluster randomized controlled trial, COPD patients $(n=425$; case method group $n=209$, traditional lectures group $n=216$ ) from 24 primary health care centers replied to questionnaires prior to and 18 months after a $2 \times 2$-h CME was given to GPs $(n=255)$. We measured changes in the scores of the Clinical COPD Questionnaire (CCQ), symptoms, needs for disease information, exacerbations, smoking, and use of pulmonary rehabilitation. The changes over time were similar for both CME methods. Patients who had used pulmonary rehabilitation increased from 13.2 to $17.8 \%(P=0.04)$, and prevalence of smoking decreased from 28.9 to $25.1 \%(P=0.003)$. In conclusion, neither of the used CME methods was superior than the other regarding patient outcomes. CME's primary value may lay in improving GPs' adherence to guidelines, which should lead to long-term positive changes in patient health.

npj Primary Care Respiratory Medicine (2020)30:44; https://doi.org/10.1038/s41533-020-00204-w

\section{INTRODUCTION}

Chronic obstructive pulmonary disease (COPD) is a public health burden that causes suffering and mortality. The Global Initiative for Obstructive Lung Disease (GOLD) guidelines aim to improve quality of life and prognosis by recommending treatments to reduce symptoms and prevent exacerbations ${ }^{1}$. The current treatment recommendations for patients with moderate to severe COPD are based on both non-pharmacological treatments (e.g., smoking cessation, pulmonary rehabilitation, and nutritional therapy) and pharmacological treatments. Assessments of disease progress and therapeutic choices are mainly made by monitoring the development of symptoms and exacerbations. Optimal COPD care can best be delivered via person-centered care given by interprofessional teams. In Sweden, the majority of patients with COPD are managed in primary health care. However, as elsewhere, there is a continuing need for improvements in general practitioners' (GPs) adherence to guidelines ${ }^{2}$.

Continuing medical education (CME) is commonly used to improve guideline implementation in clinical practice. Two examples of short educational outreach visits that are popular among GPs are participatory case method learning ${ }^{3}$ and didactic, traditional lectures. However, educational researchers have questioned the effectiveness of didactic teaching methods ${ }^{4}$. Moreover, research in Swedish primary health care shows that case-based training is associated with decreased mortality in patients with coronary heart disease ${ }^{5}$. This evidence about teaching methods led us to design and conduct PRIMAIR, a pragmatic cluster randomized controlled trial to improve COPD guideline adherence in GPs in Stockholm, Sweden, using and comparing two CME methods ${ }^{6}$. The first published results of PRIMAIR described the educational outcomes in GPs. We observed that both case method learning and traditional lectures led to modest, but equally significant improvements in GPs' levels of knowledge about
$\mathrm{COPD}^{7}$. To gain information about whether GPs' CME improved the management of COPD and patients' health status, this part of PRIMAIR included an assessment of clinical (patient) outcomes. We hypothesized that case method learning would be better than traditional lectures at improving health-related outcomes in patients with COPD.

This study aimed to compare and describe the effects of two educational methods used for GPs' education in COPD, regarding patient outcomes including health status, symptoms, patients' perceived information needs about COPD, exacerbations, smoking, and health-care visits.

\section{RESULTS}

Description of the patients

At baseline, 542 patients completed the questionnaire (response rate $57 \%$ ), and at 18 months, 425 replied to the follow-up questionnaire (final response rate 44\%) (Fig. 1). The nonresponders at baseline were slightly younger than the responders (mean age 70.3 vs. 72.0 years, $P=0.01$ ) and more of them were in GOLD stage $2(68 \%$ vs. $57 \%, P=0.001)$. The drop-out rate between baseline and 18 months was independent of CME arm, patient's age, gender, lung function, exacerbation rate, health status (scores in Clinical COPD Questionnaire (CCQ), COPD Assessment Test (CAT), and modified Medical Research Council dyspnea scale (mMRC), the body mass index, smoking status, level of education, and whether the patient was living alone or not.

There were no important differences in the baseline characteristics of the patients in the two study arms (Table 1). A higher percentage of patients in the case method learning arm than the traditional lecture arm attended a primary health care center (PHCC) with a nurse-led asthma/COPD clinic (62\% vs $49 \%$, $P=0.002)$.

\footnotetext{
${ }^{1}$ Karolinska Institutet, Department of Medicine, Division of Clinical Epidemiology, SE-171 76 Stockholm, Sweden. ${ }^{2}$ Academic Primary Health Care Centre, Stockholm County Council, Box 45436, SE-104 31 Stockholm, Sweden. ${ }^{3}$ Karolinska Institutet, NVS, Section for Family Medicine and Primary Care, Alfred Nobels Allé 23 , Huddinge, SE-141 83 Stockholm, Sweden. ${ }^{4}$ Uppsala University, Department of Public Health and Caring Sciences, Family Medicine and Preventive Medicine, Box 564 , SE-751 22 Uppsala, Sweden. ${ }^{5}$ Lund University, Center for Primary Health Care Research, Department of Clinical Sciences, SE-205 02 Malmö, Sweden. ${ }^{\circledR}$ email: hanna.sandelowsky@ki.se
} 


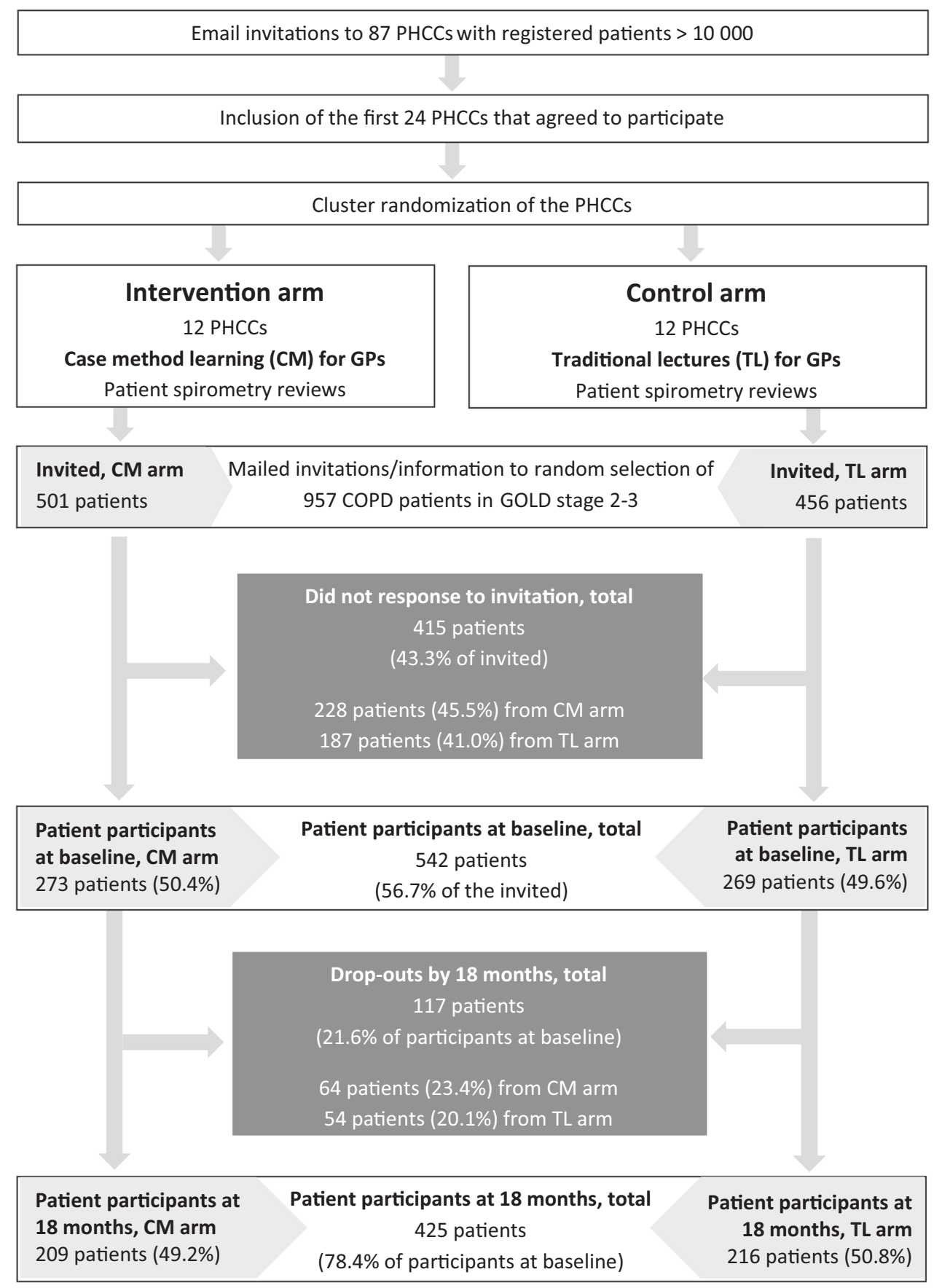

Fig. 1 Trial enrollment flow chart. PHCC primary health care center.

None of the patient outcomes at 18 months differed between the arms (Table 2). However, within each arm, there were significant changes over time in several of the outcomes (Table 3 ).

In the study group as a whole, the total scores of the $\mathrm{CCQ}^{8}$ and the $\mathrm{CAT}^{9}$, increased significantly over time from 1.87 to 1.97 and from 15.1 to 16.3 , respectively, i.e., the health status slightly deteriorated over time. However, although statistically significant, the changes in the total scores were not clinically relevant ${ }^{10,11}$. The scores in the CCQ domains "symptoms" and "functionality" also increased between baseline and follow-up, whereas scores in the domain "mental health" remained unchanged. CCQ scores at 18 months were not associated with gender, age, or presence of cardiovascular comorbidity. However, patients who had anxiety/ depression, obstructive sleep apnea, or chronic pain at baseline had clinically significantly higher CCQ scores at 18 months than patients who did not have these comorbidities.

The proportion of patients who had seen a physiotherapist increased over the study period $(13.2-17.8 \%, P=0.04)$. A significant percentage of the patients had stopped smoking; smoking prevalence decreased from $28.9 \%$ to $25.1 \%(P=0.008)$. The percentage of smokers who had been offered smoking cessation support by a health-care professional increased from 51.2 to $61.9 \%(P=0.038)$.

\section{DISCUSSION}

The 18-month follow-up of this pragmatic, real-life cluster randomized controlled trial of 542 COPD patients from 24 


\begin{tabular}{|c|c|c|c|c|}
\hline \multicolumn{5}{|l|}{ Age } \\
\hline Years, mean $[95 \% \mathrm{Cl}]$ & $71.8[71.0-72.6]$ & $72.6[71.4-73.7]$ & $71.0[69.9-72.1]$ & n.s. \\
\hline \multicolumn{5}{|l|}{ Age distribution, $n(\%)$, years } \\
\hline Age $35-64$ & 73 (17.2) & $26(12.4)$ & $47(21.8)$ & 0.014 \\
\hline \multicolumn{5}{|l|}{ Gender } \\
\hline Female, $n(\%)$ & $267(62.8)$ & $128(61.2)$ & $120(55.6)$ & n.s. \\
\hline \multicolumn{5}{|l|}{ Education } \\
\hline$\leq 9$ years, $n(\%)$ & $221(54.6)($ missing data $=20)$ & $104(52.8)$ & $117(56.3)$ & n.s. \\
\hline \multicolumn{5}{|l|}{ Smoking intensity } \\
\hline
\end{tabular}

Table 2. Patient outcomes as difference in differences (DiD) between baseline and at 18 months comparing case method learning to traditional lectures and expressing treatment effect as ( $\Delta$ score and $\Delta \%$ units) $(n=425)$.

\begin{tabular}{|c|c|c|c|c|c|c|}
\hline \multirow[t]{3}{*}{ Patient outcomes } & \multicolumn{6}{|c|}{ Educational method } \\
\hline & \multicolumn{2}{|c|}{ Case method learning } & \multicolumn{2}{|c|}{ Traditional lectures } & \multicolumn{2}{|c|}{ Difference in differences (DiD) } \\
\hline & $\begin{array}{l}\text { Baseline } \\
\text { Mean }(95 \% \mathrm{Cl})\end{array}$ & $\begin{array}{l}18 \text { months } \\
\text { Mean }(95 \% \mathrm{Cl})\end{array}$ & $\begin{array}{l}\text { Baseline } \\
\text { Mean }(95 \% \mathrm{Cl})\end{array}$ & $\begin{array}{l}18 \text { months } \\
\text { Mean }(95 \% \mathrm{Cl})\end{array}$ & & \\
\hline $\mathrm{CCQ}^{\mathrm{b}}$ & $1.84(1.68-2.00)$ & $1.97(1.81-2.14)$ & $1.89(1.73-2.06)$ & $1.97(1.81-2.13)$ & 0.05 & $0.64(-0.16$ to 0.26$)$ \\
\hline $\mathrm{CAT}^{\mathrm{C}}$ & $14.7(13.6-15.8)$ & $16.2(15.1-17.4)$ & $15.5(14.4-16.6)$ & $16.3(15.2-17.5)$ & 0.67 & $0.21(-0.37$ to 1.72$)$ \\
\hline \multirow[t]{2}{*}{$\operatorname{LINQ}^{d}$} & $11.0(10.5-11.6)$ & $10.7(10.1-11.3)$ & $10.8(10.3-11.3)$ & $10.6(10.1-11.1)$ & -0.19 & $0.71(-1.16$ to 0.78$)$ \\
\hline & Baseline \% & 18 months \% & Baseline \% & 18 months \% & $\Delta \%$ units $^{\mathrm{e}}$ & $P$ value $(95 \% \mathrm{Cl})$ \\
\hline Current smokers & 29.7 & 27.8 & 28.2 & 22.4 & 3.3 & $0.15(-1.2$ to 7.9$)$ \\
\hline$m M R C^{f} \geq 2$ points & 43.9 & 56.1 & 43.4 & 50.0 & 5.3 & 0.34 ( -5.5 to 16.1$)$ \\
\hline $\begin{array}{l}\text { Exacerbations } \\
\text { (one or more, } \\
\text { past } 6 \text { months) }\end{array}$ & 33.5 & 34.7 & 33.3 & 34.1 & 0.4 & $0.93(-9.9$ to 10.7$)$ \\
\hline $\begin{array}{l}\text { Assigned general } \\
\text { practitioner }\end{array}$ & 71.6 & 64.0 & 72.1 & 61.5 & 3.4 & $0.51(-6.8$ to 13.6$)$ \\
\hline $\begin{array}{l}\text { Visited COPD nurse } \\
\text { (past } 12 \text { months) }\end{array}$ & 36.5 & 36.2 & 37.5 & 41.0 & -3.4 & $0.50(-16.8-10.0)$ \\
\hline $\begin{array}{l}\text { Visited physiotherapist } \\
\text { (past } 12 \text { months) }\end{array}$ & 10.6 & 16.8 & 15.7 & 18.8 & 3.0 & $0.49(-5.5$ to 11.6$)$ \\
\hline $\begin{array}{l}\text { Visited occupational } \\
\text { therapist } \\
\text { (past } 12 \text { months) }\end{array}$ & 2.9 & 6.1 & 4.2 & 5.6 & 1.8 & $0.52(-3.6$ to 7.2$)$ \\
\hline $\begin{array}{l}\text { Visited nutritionist (past } \\
12 \text { months) }\end{array}$ & 3.4 & 8.1 & 9.7 & 9.4 & 5.1 & $0.18(-2.3$ to 12.5$)$ \\
\hline \multicolumn{7}{|c|}{$\begin{array}{l}\text { Cl confidence interval. } \\
\text { a } \Delta \text { scores }=[\text { difference (18 months - baseline) in scores in case method learning arm] - [difference in scores in traditional lectures arm]. Please see the } \\
\text { "Statistics" section for an explanation of the calculations. } \\
\text { bThe Clinical COPD Questionnaire. } \\
\text { cThe COPD Assessment Test. } \\
{ }^{{ }^{T}} \text { The Lung Information Needs Questionnaire. } \\
{ }^{~} \Delta \% \text { units }=[\Delta \% \text { units ( } 18 \text { months - baseline) in case method learning arm }]-[\Delta \% \text { units in traditional lectures arm]. Please see the "Statistics" section for an } \\
\text { explanation of the calculations. } \\
\text { fThe Modified Manchester Research Council Dyspnea Scale. }\end{array}$} \\
\hline
\end{tabular}


H Sandelowsky et al.

Table 3. Patient outcomes in the whole study population $(n=425)$ as difference in scores (\%) between baseline and 18 months $(\Delta$ scores and $\Delta \%$ units) when adjusted for clusters (primary health care centers) and for nurse-led COPD clinics.

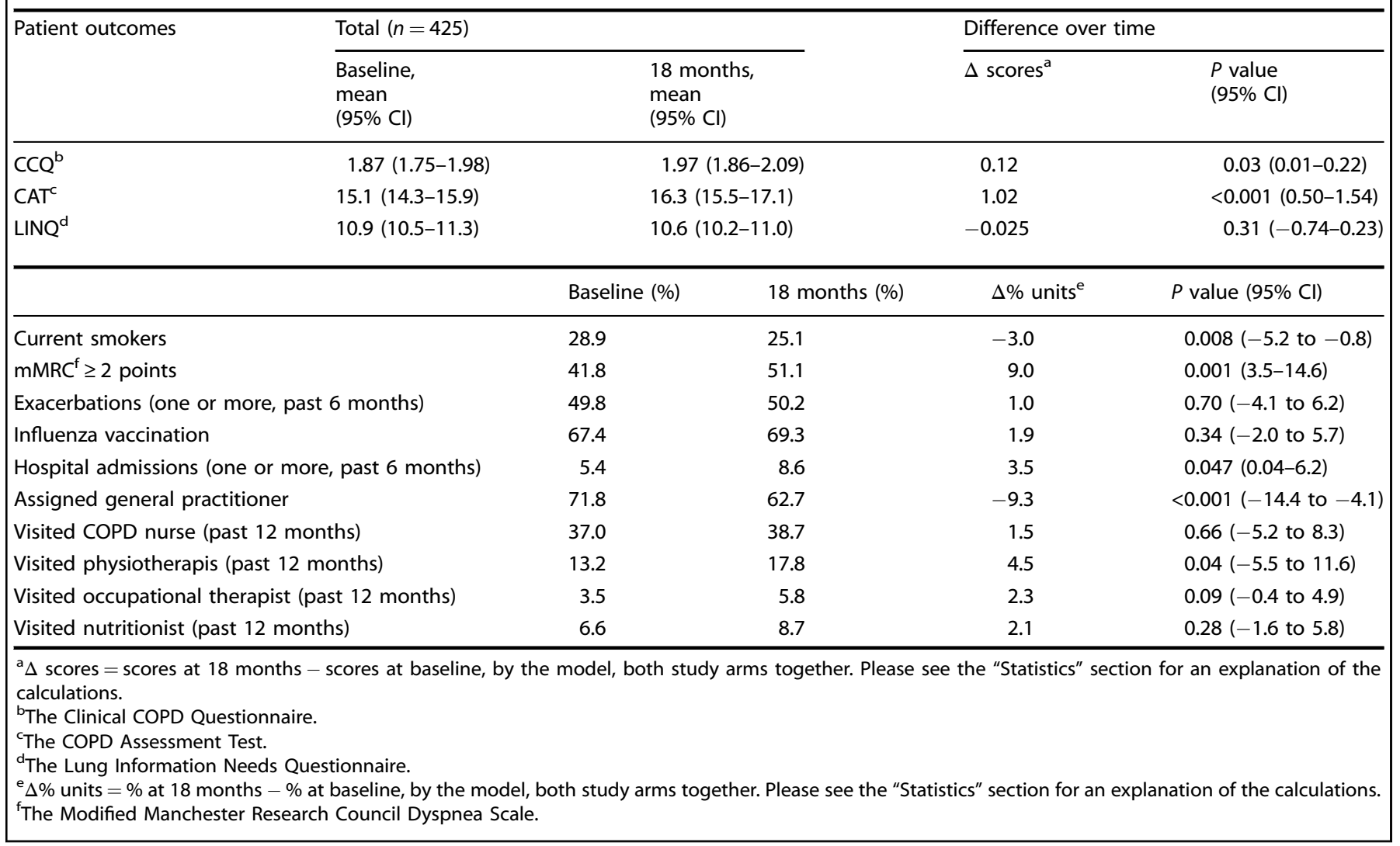

Swedish PHCCs did not support our hypothesis: short CME sessions for GPs using case method learning did not lead to greater improvements in patient-related health outcomes than did short traditional lectures. However, in the study population as a whole, the percentage of patients who had received pulmonary rehabilitation increased and the percentage of smokers decreased. These findings may have been an effect of changes in GPs' management of COPD caused by meeting the intended learning outcomes (ILOs) of PRIMAIR's CME sessions. Independent of the CME method, the significant changes in patients' health status, symptoms, frequency of exacerbations, and hospital admissions indicated slight but general worsening of COPD.

In our study, traditional lectures, representing didactic CME methods, were as effective as the more participatory case method learning when applied at short sessions for GPs. However, results from previous research discourage CME educators from using didactic CME methods and rather suggest the use of multiple, participatory, educational activities as they have shown to enhance learning more than didactic educational methods ${ }^{12,13}$. As didactic CME is the type of CME GPs often prefer ${ }^{14}$, and as it is easy to conduct and apply in practice, we argue that these traditional CME lectures should not be overlooked as a useful learning method for GPs.

Evidence on the most effective and feasible types of CME is still incomplete $^{15}$. Compared to educational and pedagogical research about undergraduate learning, CME research is a fairly young discipline. To contextualize the results of the current study, it is essential to understand the difficulties of studying the effects of single CME interventions. For example, individual CME interventions, like the one in in this study, do not generally result in large absolute effect sizes. On the basis of the statement of The Cochrane Effective Practice and Organisation of Care Group ${ }^{16}$, in
2012, Grimshaw et al. concluded that systematic reviews should be used to evaluate and develop CME programs. They reasoned that studies about individual CME interventions may be misleading because of bias in their conduct or random variations in their findings $s^{15}$.

At the 18-month follow-up, we found an increase in the percentage of patients who used pulmonary rehabilitation and decrease in percentage of current smokers. These findings may be related to disease progress, or $\mathrm{GPs}^{\prime}$ improved adherence to guidelines, or both. Other CME projects have led to increased use of pulmonary rehabilitation ${ }^{17}$, so we reason that the CME in in this study may have had similar effects. Previously published results on PRIMAIR's baseline data showed that the participating GPs had a high level of knowledge about smoking cessation support ${ }^{18}$, yet they rarely offered smoking cessation support to patients ${ }^{19}$. The improvements in the level of smoking cessation support and the reduction in the number of patients who still smoked might thus have been effects of the CME. On the other hand, patients whose COPD continues to deteriorate, as in our study population, are often motivated to quit smoking ${ }^{20}$.

We observed a small deterioration in COPD measured as increased CCQ and CAT scores over the 18-month study period. Previously, the progression of COPD was determined by the decline in FEV1 (ref. ${ }^{21}$ ), but it is now known to be associated with heterogeneous factors ${ }^{22}$. In line with the updated GOLD A-D classification of COPD ${ }^{1}$, Singh et al. ${ }^{23}$ have recently emphasized the importance of carefully assessing disease burden in individual patients rather than relying solely on spirometry data to plan for long-term COPD management ${ }^{23}$. Current best practice is for clinicians to use questionnaire-based tools to predict the progression of COPD ${ }^{1}$. The CCQ and the CAT are validated for assessing the COPD-specific health status, and the CCQ is useful in 
predicting mortality in patients with $\mathrm{COPD}^{24}$. Although the changes we found in CCQ and CAT scores were statistically significant, neither of these changes met the criteria for clinical important difference ${ }^{10,11}$.

In our study population, $80 \%$ of the patients had one or more chronic diseases in addition to COPD. COPD is increasingly recognized as a multicomponent disease with systemic consequences and effects on quality of life ${ }^{25}$, and it is not clear whether the CCQ and the CAT fully assess the impact of multimorbidity in this study. To improve the multidimensional evaluation of the progress of COPD, we therefore added clinically relevant and easily assessed outcomes. Specifically, the findings about hospital admissions and worsened exertion dyspnea strengthened our perception of disease progress.

Conducting and completing this type of pragmatic, real-life study about the patient outcomes of CME methods for GPs was an important achievement in itself as researchers and educators have called for studies on the clinical effectiveness of CME interventions ${ }^{15}$. CME research is particularly challenging to conduct because of the high demands for time and resources combined with challenges of real-life studies.

However, the pragmatic, real-life study design was primarily a strength as it enabled us to address outcomes in routine primary health care. Using short $(2 \times 2 \mathrm{~h}) \mathrm{CME}$ sessions reflected the reallife CME situation for most GPs in Sweden today. Additionally, using self-reported data, such as symptoms, quality of life, and exacerbations gave first-hand information from patients on the effects of the COPD care provided by the participating GPs. Including several established outcome measures for COPD strengthened this study, as well as using new interesting outcomes, such as patients' perceived information needs and care contacts within the interprofessional team.

This study evinced some of the limitations inherent in pragmatic trial design. Pragmatic studies are often subject to bias and confounding factors ${ }^{26}$, and a source of bias in PRIMAIR may have been the minor overlapping of the two pedagogical methods and teacher- or participant-related differences in teaching and learning. In contrast to strict, randomized controlled trials, we did not place constraints on patients, clinicians, or PHCCs during the study time. Although most of the GPs at the 24 PHCCs participated in the study at baseline, the GPs' incentives and motivation to participate in the CME and/or complete the study may have varied. Additionally, PHCCs may have differed in patient-GP continuity and staffing. Furthermore, self-reported data are not recommended for use as the sole measure of guideline adherence ${ }^{27}$, as they entail a risk of misclassification bias (misunderstanding) and recall bias.

Cluster randomization of the PHCCs strengthened the results, as it reduced the likelihood of possible contamination across GPs at each PHCC (cluster). However, a limitation of the study was the absence of a reference arm (no CME to the GPs), which was a consequence of limited research resources. Another limitation was that we had 425 rather than the 460 patients who power calculation indicated we needed. These two limitations contributed to uncertainty about whether our results were associated with the CME or were a sign of the expected and inevitable progress of the disease. However, previous results of PRIMAIR showed that the GPs who participated in the CME sessions improved their levels of knowledge about COPD more than GPs without any $\mathrm{CME}^{7}$. We therefore reason that the two $\mathrm{CME}$ methods may have had equally positive yet modest effects on some of the patient outcomes during the 18-month observation time. It would have been interesting to investigate the reasons behind the limited effects on the patient outcomes we found. This was, however, not the aim of the study. Nonetheless, we consider our results as inherently interesting as the educational methods we have studied are routinely used for GPs' CME.
As real-life studies are an important source of evidence about the effectiveness of educational methods ${ }^{28}$, the findings of this study increase knowledge about implementing CME in primary health care. This, in turn, may help educators and researchers conduct, assess, and make conclusions about CME programs that target the management of complex, chronic health issues, such as COPD. Using single CME interventions to study outcomes related to patients' health will continue to be a challenge for educational and implementation researchers, yet research in this area should continue, as every project can contribute to the evidence base for future systematic reviews and meta-analyse ${ }^{15}$. Opportunities and time to attend evidence-based educational activities and collegial discussions should be the cornerstone of professional development of primary care clinicians. It is important to understand and regard professional development and CME as a long-term project, in which acquiring new knowledge and skills always is based on, and adds on, to what the individual knows before.

In summary, there were no differences between participatory (case method learning) and didactic (traditional lecture) CME methods for GPs, when the effectiveness of these methods was assessed by studying the changes in COPD patients' health outcomes over 18 months. However, regardless of which of these CME types the GPs participated in, the prevalence of smoking decreased and use of pulmonary rehabilitation increased in the patients. CME's primary value may thus lay in improving GPs' adherence to guidelines, which should lead to long-term positive changes in patient health.

\section{METHODS}

We used the 2010 Consolidated Standards of Reporting Trials (CONSORT) statement: extension for cluster randomized trials ${ }^{29}$, the CONSORT checklist (Supplementary Table 1), and flow chart (Fig. 1). The present cluster randomized controlled trial ${ }^{6}$, including a model consent form and other related documentation given to participants, was approved by the Regional Ethical Review Board of Stockholm (ref 2013/232-31/5). Prior to patient enrollment, all PHCC managers and GPs provided written informed consent to be involved in the study. All patients provided written informed consent to participate in the study and they were allocated to the same study arm as their GPs. The study was registered at www.clinicaltrials.gov on 10 August 2014, Identifier NCT02213809. The first participant was enrolled 14 August 2014.

\section{Patient recruitment}

The study enrollment for the parts of PRIMAIR that involved patients followed the cluster randomization of the patients' PHCCs (Fig. 1). Both GPs and patients were recruited in 2014, after the research group first had computer randomized the 24 participating PHCCs (clusters) in Stockholm County, Sweden, to one of two study arms. The included PHCCs had the minimum of 10,000 registered patients and thus several GPs. In one of the arms, GPs were given CME $(2 \times 2 \mathrm{~h})$ via case method learning ( 12 PHCCs) and in the other arm traditional lectures (12 PHCCS) were used. Apart from few exceptions, all the GPs on duty on the days of the CME sessions took part in the CME.

The research group identified all patients with a diagnosis of COPD in the PHCCs' medical records. They then confirmed the diagnoses by applying GOLD 2013 guidelines ${ }^{30}$ to the spirometry results in patients' electronic medical records. The guidelines defined COPD as the ratio of forced expiratory volume of one second and forced vital capacity (FEV1/ FVC) $<0.70$. Patients with FEV1, 30-79\% of predicted, after bronchodilatation (GOLD stages 2 and 3), were included in the study. The sample size was determined by a power calculation based on the mean and standard deviation of the $\mathrm{CCQ}^{8}$ and the minimal clinically important difference (MCID) of 0.4 in the $C C^{10}$. This resulted in the need for a minimum of 230 patients in each study arm. On the basis of earlier studies on cluster randomization in primary care ${ }^{31-33}$, we used the intraclass correlation coefficient of 0.01 in the power calculation. A total of 957 randomly selected patients were invited to participate, $40-45$ from each PHCC. 


\section{CME sessions for GPs}

Five teachers, all GPs competent and experienced in COPD management, ran two 2-h sessions at each PHCC during 2014-2015. The first session was held after the baseline data from the patients were collected, and the other session a maximum of 3 months later. One teacher used case method learning at 12 PHCCs and four teachers used traditional lectures (each at 2-4 PHCCS). The learning outcomes (ILOs), activities, and assessments of the CME were aligned in accordance with John Biggs ${ }^{\prime 34}$ theory of constructive alignment. The ILOs were derived from pre-2015 COPD guidelines $^{30,35,36}$ and from a 2013 qualitative study that described GPs' experiences of barriers to and facilitators of implementing COPD guidelines ${ }^{37}$. In short, the ILOs included knowledge about approaches to diagnostics, treatments (both pharmacological and non-pharmacological), and monitoring of patients with COPD in primary care settings ${ }^{6}$.

The case method learning activities were interactive rather than didactic. At a case method learning seminar, the teacher facilitated a discussion about one or two open-ended, real-life narratives (i.e., cases) that were written from a profession-specific perspective ${ }^{38}$. Participating in case method learning required previous knowledge and clinical experience in the subject. The primary aim of case method learning techniques was to improve clinical decision-making skills.

The traditional lectures were semi-didactic; that is, the lectures could include short patient case vignettes that may or may not have led to some interaction between the teacher and the participants. At these lectures, the teacher had the role of an academic expert. Traditional lectures primarily aimed to reduce knowledge barriers at the level of the individual participant.

\section{Data collection}

Patient data were collected by mailing the patients the same questionnaire (Supplementary Methods) at baseline (2014) and at 18 months.

The primary outcome measure was the total CCQ score. The CCQ assesses disease-related health status, including airway symptoms, limitations in physical activity (functionality), and emotional dysfunction (mental health) $^{8}$. The questions apply to the previous week. The CCQ uses a seven-point scale from 0 to 6 , and total score is calculated as the mean of the sum of all the items. Higher values indicate worse health status; the MCID is 0.4 units $^{10}$.

The secondary outcome measures included the total CAT score ${ }^{9}$, which assesses the impact of COPD symptoms on health status (scale 0-40; higher values indicate worse symptoms and health status, MCID $=2$ points ${ }^{11}$ ); the total mMRC score ${ }^{39}$, which grades the impact of breathlessness on daily activities (scale $0-4$; higher values indicate more dyspnea); and the total Lung Information Needs Questionnaire (LINQ) score $^{40}$, which assesses patients' perceived needs for information about COPD (scale 0-25, higher values indicate greater needs for information). Additional secondary outcomes were exacerbations, comorbidities, health care visits, smoking, treatments, and education levels. This information was gathered via the patient questionnaires.

A COPD exacerbation was defined as a patient-reported intermittent period of deterioration in the disease in the previous 6 months that had warranted an unscheduled or emergency visit to a PHCC or hospital and/or additional medication with antibiotics and/or oral steroids.

\section{Statistics}

We performed the statistical analysis with STATA version 14 (ref. ${ }^{41}$ ) and SPSS version 25 (ref. ${ }^{42}$ ). We used SPSS to calculate summary statistics such as means, proportions, and confidence intervals with standard methods. In STATA, we used random-effects models with robust standard errors, xtreg for continuous variables, and xtlog for dichotomous variables to analyze the difference in differences (DiD) between the two CME methods over time. Both methods adjusted for clusters and for whether there was an asthma/COPD clinic at the PHCC. First, the difference in outcome between 18 months and baseline was estimated separately for the case method learning arm and the traditional lectures arm. Second, the DiD was estimated by applying the methods described above completed by margins. Margins are post-estimation statistics calculated from predictions of a previously fit model at fixed values of some covariates and averaging over the remaining covariates ${ }^{43}$. The contrast between the marginal effects of time in the two study arms was the average effect in the probability (dichotomous outcomes) or in scores (continuous outcomes).

The DiD of the outcome probabilities (or scores) was estimated using the margins. The result was the average difference in the probability (or in scores) of $y$ between $x=0$ (case method learning) and $x=1$ (traditional lectures). The results are shown as $\Delta \%$ for dichotomous outcomes or $\Delta$ score for continuous outcomes or $P$ values of $<0.05$ were considered statistically significant.

\section{Reporting summary}

Further information on research design is available in the Nature Research Reporting Summary linked to this article.

\section{DATA AVAILABILITY}

Data analyzed in this study are available from the corresponding author in response to requests that comply with ethical principles of good research.

\section{CODE AVAILABILITY}

SPSS and STATA syntax files can be requested by sending an e-mail to the corresponding author.

Received: 14 May 2020; Accepted: 23 September 2020; Published online: 15 October 2020

\section{REFERENCES}

1. Global Initiative for Chronic Obstructive Lung Disease 2020. http://www. goldcopd.com/ (2020).

2. Stallberg, B. et al. Management, morbidity and mortality of COPD during an 11year period: an observational retrospective epidemiological register study in Sweden (PATHOS). Prim. Care Respir. J. 23, 38-45 (2014).

3. Mauffette-Leenders, L. A., Erskine, J. A. \& Leenders, M. R. Learning with Cases. 1-132 (Richard Ivey School of Business, The University of Western Ontario, 1997).

4. Forsetlund, L. et al. Continuing education meetings and workshops: effects on professional practice and health care outcomes. Cochrane Database Syst. Rev. CD003030. https://doi.org/10.1002/14651858.CD003030.pub2 (2009).

5. Kiessling, A., Lewitt, M. \& Henriksson, P. Case-based training of evidence-based clinical practice in primary care and decreased mortality in patients with coronary heart disease. Ann. Fam. Med. 9, 211-218 (2011).

6. Sandelowsky, H., Krakau, I., Modin, S., Stallberg, B. \& Nager, A. Case method in COPD education for primary care physicians: study protocol for a cluster randomised controlled trial. Trials 18, 197 (2017).

7. Sandelowsky, H. et al. Effectiveness of traditional lectures and case methods in Swedish general practitioners' continuing medical education about COPD: a cluster randomised controlled trial. BMJ Open 8, e021982 (2018).

8. van der Molen, T. et al. Development, validity and responsiveness of the Clinical COPD Questionnaire. Health Qual. Life Outcomes 1, 13 (2003).

9. Jones, P. W. et al. Development and first validation of the COPD Assessment Test. Eur. Respir. J. 34, 648-654 (2009).

10. Kocks, J. W. et al. Health status measurement in COPD: the minimal clinically important difference of the clinical COPD questionnaire. Respir. Res. 7, 62 (2006).

11. Kon, S. S. et al. Minimum clinically important difference for the COPD Assessment Test: a prospective analysis. Lancet Respir. Med. 2, 195-203 (2014).

12. Davis, D., Galbraith, R. \& American College of Chest Physicians Health and Science Policy Committee. Continuing medical education effect on practice performance: effectiveness of continuing medical education: American College of Chest Physicians Evidence-Based Educational Guidelines. Chest 135, 42S-48S (2009)

13. Mazmanian, P. E., Davis, D. A., Galbraith, R. \& American College of Chest Physicians Health and Science Policy Committee. Continuing medical education effect on clinical outcomes: effectiveness of continuing medical education: American College of Chest Physicians Evidence-Based Educational Guidelines. Chest 135, 49S-55S (2009).

14. Yee, M., Simpson-Young, V., Paton, R. \& Zuo, Y. How do GPs want to learn in the digital era? Aust. Fam. Physician 43, 399-402 (2014).

15. Grimshaw, J. M., Eccles, M. P., Lavis, J. N., Hill, S. J. \& Squires, J. E. Knowledge translation of research findings. Implement Sci. 7, 50 (2012).

16. Effective Practice and Organisation of Care Group. https://epoc.cochrane.org/ (2011).

17. Anastasaki, M. et al. Establishing a pulmonary rehabilitation programme in primary care in Greece: a FRESH AIR implementation study. Chron. Respir. Dis. 16, 1479973119882939 (2019).

18. Sandelowsky, H. et al. COPD management by Swedish general practitionersbaseline results of the PRIMAIR study. Scand. J. Prim. Health Care 1-9. https://doi. org/10.1080/02813432.2018.1426148 (2018). 
19. Sandelowsky, H., Krakau, I., Modin, S., Stallberg, B. \& Nager, A. COPD patients need more information about self-management: a cross-sectional study in Swedish primary care. Scand. J. Prim. Health Care 37, 459-467 (2019).

20. Stegberg, M. et al. Changes in smoking prevalence and cessation support, and factors associated with successful smoking cessation in Swedish patients with asthma and COPD. Eur. Clin. Respir. J. 5, 1421389 (2018).

21. Vestbo, J. et al. Changes in forced expiratory volume in 1 second over time in COPD. N. Engl. J. Med. 365, 1184-1192 (2011).

22. Casanova, C. et al. The progression of chronic obstructive pulmonary disease is heterogeneous: the experience of the BODE cohort. Am. J. Respir. Crit. Care Med. 184, 1015-1021 (2011).

23. Singh, D., D'Urzo, A. D., Donohue, J. F. \& Kerwin, E. M. Weighing the evidence for pharmacological treatment interventions in mild COPD; a narrative perspective. Respir. Res. 20, 141 (2019).

24. Sundh, J., Janson, C., Lisspers, K., Montgomery, S. \& Stallberg, B. Clinical COPD Questionnaire score (CCQ) and mortality. Int. J. Chron. Obstruct. Pulmon. Dis. 7, 833-842 (2012).

25. Putcha, N., Drummond, M. B., Wise, R. A. \& Hansel, N. N. Comorbidities and chronic obstructive pulmonary disease: prevalence, influence on outcomes, and management. Semin. Respir. Crit. Care Med. 36, 575-591 (2015).

26. Blonde, L., Khunti, K., Harris, S. B., Meizinger, C. \& Skolnik, N. S. Interpretation and impact of real-world clinical data for the practicing clinician. Adv. Ther. 35 1763-1774 (2018).

27. Adams, A. S., Soumerai, S. B., Lomas, J. \& Ross-Degnan, D. Evidence of self-report bias in assessing adherence to guidelines. Int. J. Qual. Health Care 11, 187-192 (1999).

28. Luce, B. R. et al. EBM, HTA, and CER: clearing the confusion. Milbank Q. 88 256-276 (2010).

29. Campbell, M. K., Piaggio, G., Elbourne, D. R. \& Altman, D. G. Consort 2010 statement: extension to cluster randomised trials. BMJ 345, e5661 (2012).

30. Global Initiative for Chronic Obstructive Lung disease. http://www.goldcopd. $\mathrm{com} /(2013)$

31. Adams, G. et al. Patterns of intra-cluster correlation from primary care research to inform study design and analysis. J. Clin. Epidemiol. 57, 785-794 (2004).

32. Killip, S., Mahfoud, Z. \& Pearce, K. What is an intracluster correlation coefficient? Crucial concepts for primary care researchers. Ann. Fam. Med 2, 204-208 (2004)

33. Hayes, R. J., Moulton, H. Cluster Randomised Trials (Chapman \& Hall/CRC, Taylor \& Francis Group, London, 2009).

34. Biggs, J. B. \& Tang, C. Teaching for Quality Learning at University (The McGraw-Hill Companies, New York, 2011).

35. National Board of Health and Welfare. Socialstyrelsens riktlinjer för vård av astma och kroniskt obstruktiv lungsjukdom (KOL). Faktadokument och beslutsstöd för prioriteringar (2004).

36. Swedish Medical Products Agency. Läkemedelsverkets riktlinjer för behandling av kroniskt obstruktiv lungsjukdom. https://lakemedelsverket.se/upload/halso-och-sjukvard/ behandlingsrekommendationer/bakg dok/KOL bakgrundsdokumentation.pdf (2015).

37. Sandelowsky, H. et al. Time pressured deprioritization of COPD in primary care: a qualitative study. Scand. J. Prim. Health Care, 1-11. https://doi.org/10.3109/ 02813432.2015 .1132892 (2016).

38. Johansson, L. \& Nordquist J. Att undervisa med case i utbildningar inom hälso- och sjukvården (Karolinska Institutet, Medical Case Centre, Stockholm, 2009).

39. Kocks, J. W., Asijee, G. M., Tsiligianni, I. G., Kerstjens, H. A. \& van der Molen, T. Functional status measurement in COPD: a review of available methods and their feasibility in primary care. Prim. Care Respir. J. 20, 269-275 (2011)

40. Jones, R. C., Wang, X., Harding, S., Bott, J. \& Hyland, M. Educational impact of pulmonary rehabilitation: lung Information needs questionnaire. Respir. Med. 102 1439-1445 (2008).

41. Stata Corp. Stata Statistical Software: Release 14 (T.S.C.L, College Station, 2015)

42. IBM Corp. Released 2017. IBM SPSS Statistics for Windows, V. A., IBM Corp, NY (2017).

43. Stata Corp. Marginal Means, Adjusted Predictions, and Marginal Effects. https:// www.stata.com/manuals15/rmargins.pdf (2014).

\section{ACKNOWLEDGEMENTS}

The authors would like to thank Scientific Editor Kimberly Kane for useful comments on the text. This work was supported by employment in and grants from the Stockholm County Council (grand register number LS 1110-1339, LS 1301-0078, and LS 1411-1373), employment in Dalarna County Council, and an unrestricted research grant from AstraZeneca Inc. The pharmaceutical industry did not participate in any part of the study, and the participants were not offered any financial incentives.

\section{AUTHOR CONTRIBUTIONS}

H.S., I.K., S.M., B.S., and A.N. conceived and designed the study. H.S. was the case method learning teacher and B.S. was one of four traditional lectures' teachers. H.S collected the data. H.S., B.S., S.E.J., and A.N. analyzed the data. H.S. wrote the paper. All authors edited, revised, and approved the final manuscript.

\section{FUNDING}

Open Access funding provided by Karolinska Institute.

\section{COMPETING INTERESTS}

H.S. has received honoraria for educational activities from Boehringer Ingelheim Novartis, AstraZeneca, Chiesi, and TEVA and an unrestricted research grant from AstraZeneca. A.N. has received compensation for educational activities from AstraZeneca and S.M. from Novartis. B.S. has received honoraria for educational activities and lectures from AstraZeneca, Boehringer Ingelheim, Chiesi, Meda, Novartis, and TEVA and has served on advisory boards arranged by AstraZeneca, Novartis, Meda, TEVA, GlaxoSmithKline, and Boehringer Ingelheim. I.K. and S.E.J. report no competing interests.

\section{ADDITIONAL INFORMATION}

Supplementary information is available for this paper at https://doi.org/10.1038/ s41533-020-00204-w.

Correspondence and requests for materials should be addressed to H.S.

Reprints and permission information is available at http://www.nature.com/ reprints

Publisher's note Springer Nature remains neutral with regard to jurisdictional claims in published maps and institutional affiliations. Attribution 4.0 International License, which permits use, sharing, adaptation, distribution and reproduction in any medium or format, as long as you give appropriate credit to the original author(s) and the source, provide a link to the Creative Commons license, and indicate if changes were made. The images or other third party material in this article are included in the article's Creative Commons license, unless indicated otherwise in a credit line to the material. If material is not included in the article's Creative Commons license and your intended use is not permitted by statutory regulation or exceeds the permitted use, you will need to obtain permission directly from the copyright holder. To view a copy of this license, visit http://creativecommons. org/licenses/by/4.0/.

(c) The Author(s) 2020 